\title{
Sistem Informasi Geografis Daerah Rawan Kriminalitas di Kabupaten Garut
}

\author{
Ridwan Setiawan ${ }^{1}$, Bardan Salam ${ }^{2}$ \\ Jurnal Algoritma \\ Sekolah Tinggi Teknologi Garut \\ Jl. Mayor Syamsu No. 1 Jayaraga Garut 44151 Indonesia \\ Email : jurnal@itg.ac.id \\ 1ridwansetiawan@itg.ac.id \\ 21606034@itg.ac.id
}

\begin{abstract}
Abstrak - Tujuan dari penelitian ini adalah membangun sebuah Sistem Informasi Geografis dimana setiap tindakan kriminal yang bersifat umum ditampilkan di titik kejadian perkara, selain itu dibutuhkan pula sebuah kanal yang memungkinkan masyarakat untuk melaporkan kejadian yang perlu ditangani oleh kepolisian, dengan penelitian ini pula mencangkup fitur untuk masyarakat memberikan kritik dan saran kepada kepolisian guna evaluasi bagi kepolisian untuk meningkatkan pelayanan. Metodologi yang digunakan untuk mencapai tujuan tersebut menggunakan metodologi Rational Unified Proccess (RUP) yang tahapannya terdiri dari Inception, Elaboration, Contruction dan Transition serta pemodelan yang akan digunakan adalah Unified Modelling Language (UML) yang terdiri dari diagram Use Case Diagram, Activity Diagram, Squence Diagram, dan Class Diagram. Penelitian ini berfokus pada tindak kejahatan pencurian kendaraan bermotor dengan menggunakan data pada tahun 2019 yang berasal dari Kepolisian Kabupaten Garut. Hasil dari penelitian berupa sistem yang dapat melihat titik lokasi kejadian tindak kriminal pencurian kendaraan bermotor dan melaporkan tindakan pidana dan menyampaikan kritik dan saran kepada kepolisian oleh masyarakat yang dikelola oleh kepolisian.
\end{abstract}

Kata Kunci - Kriminalitas; Rational Unified Proccess; Sistem Informasi Geografis.

\section{PENDAHULUAN}

Sistem informasi geografis (SIG) merupakan suatu sistem yang berkaitan satu dengan yang lainnya. Dimana SIG tersebut terdiri atas piranti yang tertata dan terdiri dari hardware komputer, software, data geografi, dan personel yang di rancang agar dapat memperoleh, memanipulasi, memperbaiki, menganalisis, menyimpan, dan memperlihatkan bentuk permukaan bumi dalam bentuk informasi [1]. Dilihat dari permukaan bumi Kabupaten Garut sangat dekat dengan kota Bandung, dimana Kabupaten Garut berada di Provinsi Jawa Barat bagian tenggara pada koordinat $6^{\circ} 56^{\prime} 49-7^{\circ} 45^{\prime} 00$ Lintang Selatan dan $107^{\circ} 25^{\prime} 8-108^{\circ} 7^{\prime} 30$ bujur timur dengan area wilayah administrasi seluas $306.519 \mathrm{Ha}\left(3.065,19 \mathrm{~km}^{2}\right)$ dengan jumlah penduduk yang tercatat dalam badan pusat statistik Kabupaten Garut selama tahun 2019 sebanyak 2.622.425 jiwa.

Berdasarkan data kepolisian di Kabupaten Garut pada tahun 2019 telah terjadi kejahatan pencurian kendaraan bermotor sebanyak 100 kasus, penggelapan 83 kasus, penipuan 79 kasus, penganiayaan sebanyak 32 kasus dan pengeroyokan sebanyak 19 kasus (Polres Garut, 2020). berdasarkan data tersebut, dapat dilihat bahwa di daerah garut banyak terjadi tindak kejahatan, adapun tindak kejahatan terbanyak yaitu pencurian kendaraan bermotor yaitu sebanyak 100 kasus, dimana banyaknya kasus tindak kejahatan curanmor tersebut desababkan oleh banyak faktor diantaranya yaitu kurangnya informasi kepada masyarakat mengenai daerah tempat terjadinya tindak kejahatan curanmor sehingga masyarakat menjadi kurang waspada terhadap tindak kejahatan ini.

Article History: $\quad$ Recivied Dec 11, $2020 \quad$ Revised Aug 9, $2021 \quad$ Accepted Aug 9, 2021 
Pentingnya penyebaran informasi kapada masyarakat merupakan salah satu tindakan pencegahan atau penanggulangan dalam menangani tindak kejahatan curanmor. Polres Garut perlu melakukan penandaan lokasi mengenai daerah-daerah yang rawan terjadi tindak kejahatan, khususnya tindak kejahatan yang banyak terjadi yaitu tindak kejahatan curanmor. Untuk penandaan lokasi tidak hanya cukup dilakukan dengan penandaan di peta saja akan tetapi perlu ada di SIG berbasis web [3] agar masyarakat juga dapat mengetahui mengenai daerah tempat yang bisasanya terjadi tindak kriminalitas. sehingga Polres Garut dapat menentukan tindakan terhadap masing-masing wilayah yang sudah di tandai dan informasi mengenai tempat biasanya terjadi tindak kriminalitas dapat diketahui oleh masyarakat sebagai tindakan antisipasi.

Terdapat bebrapa penelitian sebelumnya mengenai sistem informasi geografis, penelitian pertama membahas pengenai proses penyebaran infromasi mitigasi bencana yang belum optimal dan didapat hasil berupa aplikasi SIG dapat menjadi media infromasi penyebarab serah rawab banjir [2], penelitian kedua membahas mengenai belum dilakukannya pengamatan dari titik-titik lokasi yang sering terjadinya tindak kriminalitas kemudian dari penelitian tersebut didapatkan hasil berupa sistem informasi geografis yang menunjukan daerah rawan kriminalitas yang berupa titik lokasi [3], penelitian ketiga membahas mengenai lembaga penididikan yang belum mempunyai pengelolaan sebaran alumni dan didapat hasil perancangan SIG yang menangani pemetan derah sebaran alumni [4], peneltian keempat membahas mengenai profil wisata belum dipublikasin kepada masyarakat, kemudian didapatkan hasil berupa aplikasi Sistem Informasi Geografis profil wisata [5], penelitian kelima membahas mengenai belum adanya sebuah aplikasi pendukung dalam pemberian infrormasi kepada masyarakat mengenai lokasi sering terjadinya tindak kriminal dan didapat hasil Sistem Infromasi Geografis Lokasi Rawan Berbasis Android [6]. Dari pemaparan latar belakang diatas, maka peneliti berminat untuk melakukan penelitian selanjutnya yaitu mengenai "Sistem Informasi Gaeografis Daerah Rawan Kriminalitas Di Kabupaten Garut".

\section{METODE PENELITIAN}

Tampak beberapa tahapan dan aktivitas yang akan dilakukan pada penelitian ini dengan bertujuan untuk mencapai tujuan dalam proses perancangan sistem yang didasari oleh penelitian sebelumnya [7] dengan menggunakan metodologi Rational Unified Proccess (RUP) yang memiliki tahapan Studi Literatur, Inception, Elaboration, Construction, dan Transition yang di mana tahapan tersebut akan disajikan dalam kerangka kerja penelitian sebagaimana tampak pada Gambar 1.

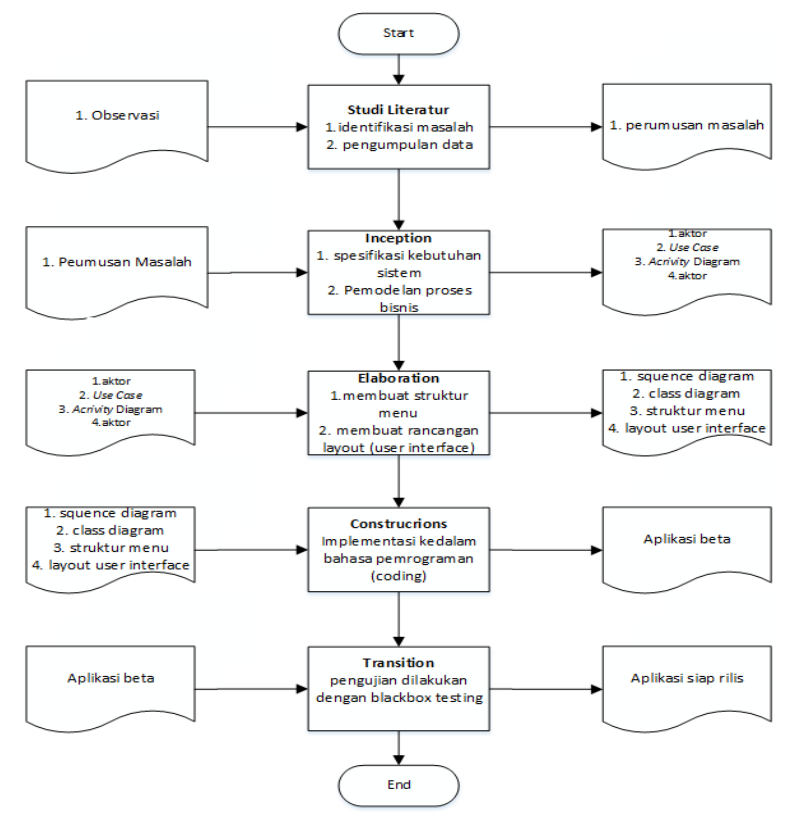

Gambar 1: Kerangka Penelitian 
1) Studi Literatur

Tahapan ini dilakukan untuk mengidentifikasi komponen-komponen yang terkait pada penelitian dengan melakukan observasi dan studi pustaka serta wawancara dengan beberapa pihak terkait.

2) Inception

Tahapan inception adalah tahap persiapan. Dimana tahapan ini dilakukan agar dapat memastikan utilitas dari software yang akan dibangun, pemodelam proses bisnis, dan perencanaan dari proyek. Analisi kebutuhan sistem berupa penentuan aktor atau pengguna, dimana aktor atau pengguna adalah semua hal diluar sistem yang akan menjadi pengguna sistem.

3) Elaboration

Tahapan elaboration adalah tahap dimana dilakukan analisis lebih lanjut dari tahap inception yaitu dengan cara menguraikan bisnis proses yang didapat pada tahap inception. Pada tahap ini lebih memfokuskan pada analisi dan desain sistem seperti membuat struktur menu, dan membuat rancangan layout (User Interface).

4) Construction

Tahapan construction adalah tahapan konstruksi, pada tahapan ini dilakukan implementasi rancangan layout (User Interface) dan rancangan struktur menu kedalam bahasa pemrograman atau biasa disebut pengkodingan sesuai ketentuan pada tahap elaboration sehingga didapat hasil aplikasi beta.

5) Transition

Pada tahapan ini adalah melakukan uji coba sistem dengan memakai pengujian black-box testing, dimana pada tahapan ini bermaksud untuk mencari bug atau kesalahan pada sistem, apakah semua fitur dan fungsi pada sistem berjalan baik atau tidak Sehingga dapat mengantisipasi terjadinya kesalahan pada sistem.

\section{HASIL DAN PEMBAHASAN}

\section{A. Hasil Penelitian}

Berdasarkan dari kerangka penelitian yang bertujuan untuk membangun sistem informasi geografis berdasarkan metodologi RUP, untuk tahapan dan aktivitasnya dalam proses membangun program dijabarkan pada pembahasan berikutnya.

\section{B. Studi Literatur}

Pada tahap ini dilakukan identifikasi masalah dengan melakukan ke lokasi penelitian yaitu di Polres Kabupaten Garut dan wawancara dengan narasumber yaitu bapak Yongki Arisandi sebagai petugas bagian Reskrim Polres Garut didapat perumusan masalah yaitu dimana Penandaan titik lokasi tindak terjadinya kriminalitas biasa dilakukan pada peta map fisik sehingga informasi mengenai derah rawan tindak terjadinya kriminalitas tidak sampai ke masyarakat.

\section{Inception}

Pada tahapan ini melakukan analisis terhadap system untuk mengetahui kebuuthan sisyem itu sendiri dengan membuat sebuah diagram use case yang memaparkan keterkaitan antara sistem dengan aktor [7]. Dimana hasil dari tahapan ini disajikan dalam bentuk gambar, sebagaimana tampak pada Gambar 2. 


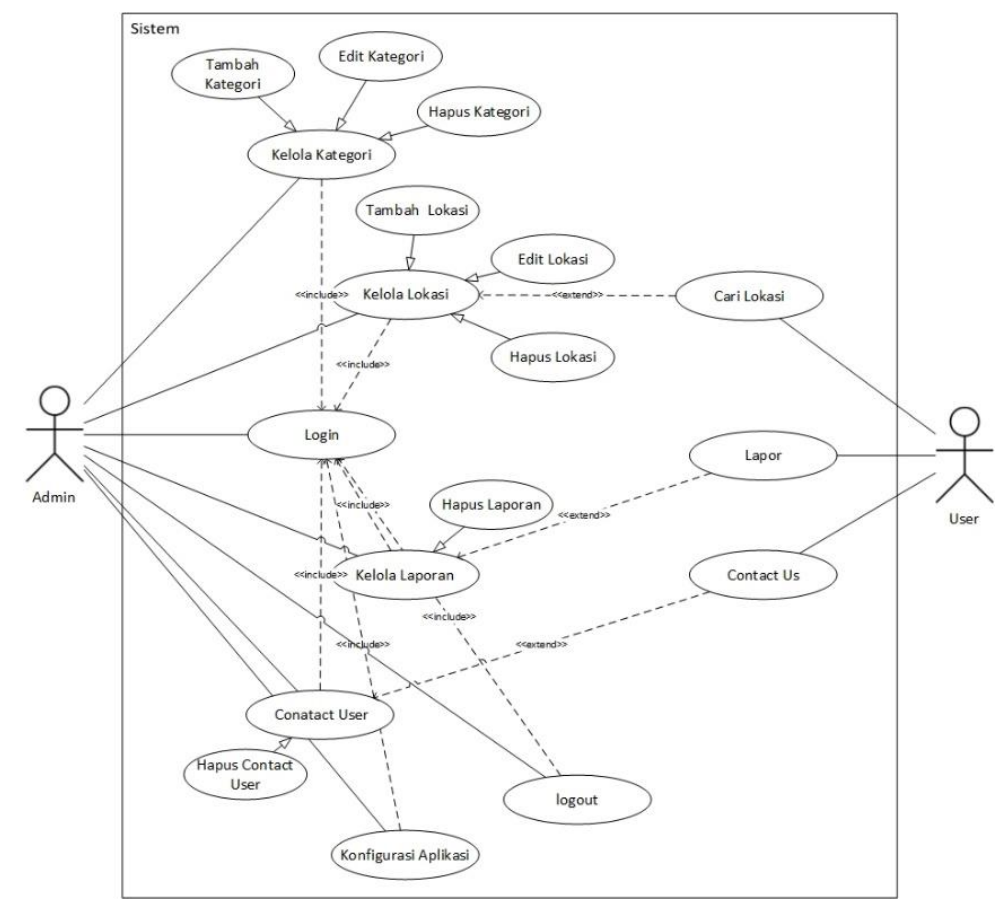

Gambar 2: Use Case Diagram

Berdasarkan pada Gambar 2, terdapat dua aktor yang menggunakan Sitem Informasi Geografis Daerah Rawan Kriminalitas di Kabupaten Garut diantaranya admin dan user. Dimana admin sebagai orang yang mengelola aplikasi secara keseluruhan dan user sebagai orang yang melihat informasi yang terdapat pada aplikasi. Berikut ini merupakan identifikasi use case yang disajikan pada Tabel 1.

Tabel 1: Identifikasi Use Case

\begin{tabular}{|c|l|l|}
\hline No & \multicolumn{1}{|c|}{ Use Case } & \multicolumn{1}{c|}{ Deskripsi } \\
\hline 1 & Login & $\begin{array}{l}\text { Hak akses untuk masuk ke aplikasi } \\
\text { mengedit, dan menghapus kategori. }\end{array}$ \\
\hline 2 & Kelola kategori & $\begin{array}{l}\text { Proses mengelola lokasi diantaranya menambah, mengedit, } \\
\text { dan menghapus lokasi. }\end{array}$ \\
\hline 3 & Kelola lokasi & Proses mengelola laporan diantaranya menghapus laporan. \\
\hline 4 & Kelola laporan & $\begin{array}{l}\text { Proses mengelola laporan diantaranya menghapus contact } \\
\text { user. }\end{array}$ \\
\hline 5 & Contact user & Proses mengelola mengkonfigurasi aplikasi. \\
\hline 6 & Konfigurasi apliksi & Proses untuk keluar dari aplikasi. \\
\hline 7 & Logout & Proses mencari lokasi. \\
\hline 8 & Cari & Proses mengrimkan keluhan, saran, maupu pesan. \\
\hline 9 & Contact us & Proses user melakukan lapor \\
\hline 10 & Lapor & \\
\hline & & \\
\hline
\end{tabular}

\section{Elaboration}

Pada tahapan ini akan berfokus pada perancangan arsitektur sistem yang akan dibuat. Dimana pada perancangan tersebut membuat perancangan sistem, membuat struktur menu, dan membuat rancangan User Interface. Hasil dari fase elaboration berupa class diagram [8] yang tampak pada Gambar 3. 


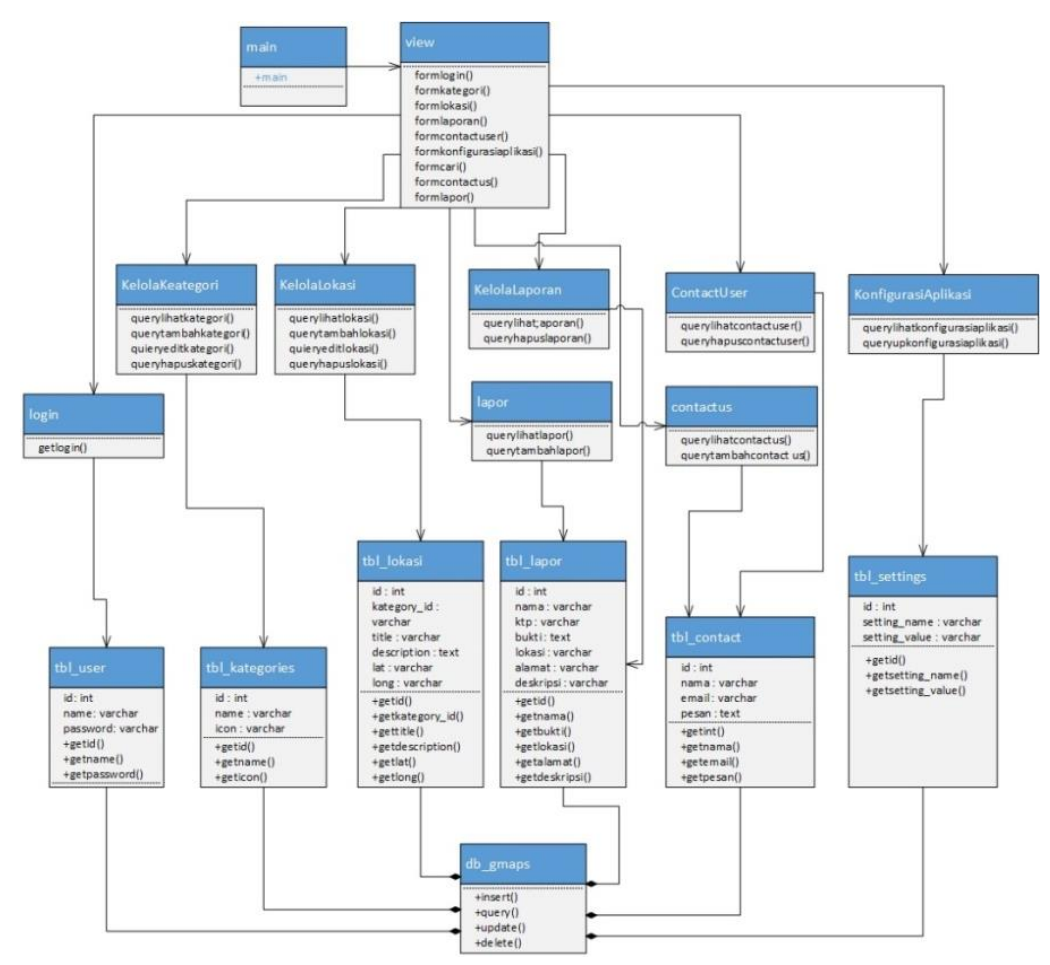

Gambar 3: Class Diagram

Berdasarkan Gambar 3, terdapat class sistem, class view, dan class data. Class system terdiri dari login, KelolaKategori, KelolaLokasi, KealolaLaporan, ContactUser, KonfigurasiAplikasi, Lapor, dan ContactUs. Class View merupakan class yang menangani tampilan. Dan Class Data terdiri dari tbl_user, tbl_kategories, tbl_lokasi, tbl_lapor, tbl_contact, tbl_settings, dan db_gmaps.

\section{E. Contruction}

Pada tahap ini dilakukan implementasi dari perancangan user interface Sistem Infromasi Geografis Derah Rawan Kriminalitas Di Kabupaten Garut dengan menggunakan bahasa pemograman PHP [9], laravel framework [10], dan DBMS yang digunakan adalah MySQL [11], sedangkan untuk mengatur keindahan tampilan digunakan framework bootstrap 4 [12]. Dimana hasil dari tahapan ini sebagaimana seperti berikut ini

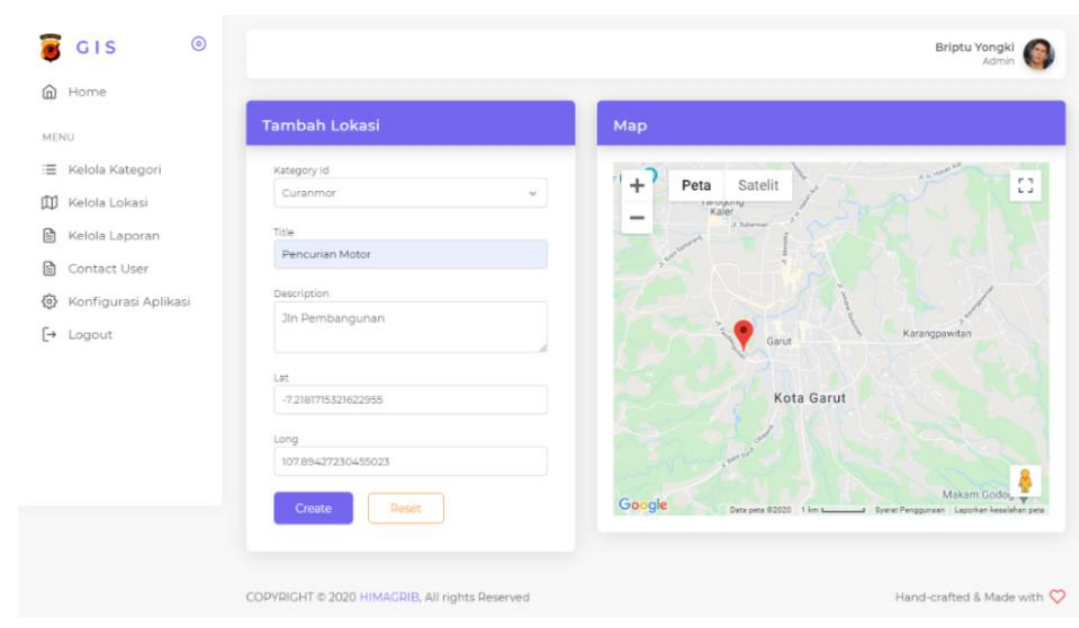

Gambar 4: Penambahan Titik Lokasi 
Pada Gambar 4 digambarkan aktivitas sistem mengenai penambahan titik lokasi dengan aktor admin, dan untuk melihat hasil penandan titik lokasi dapat dilihat pada halaman umum yang disajikan pada Gambar 5 :

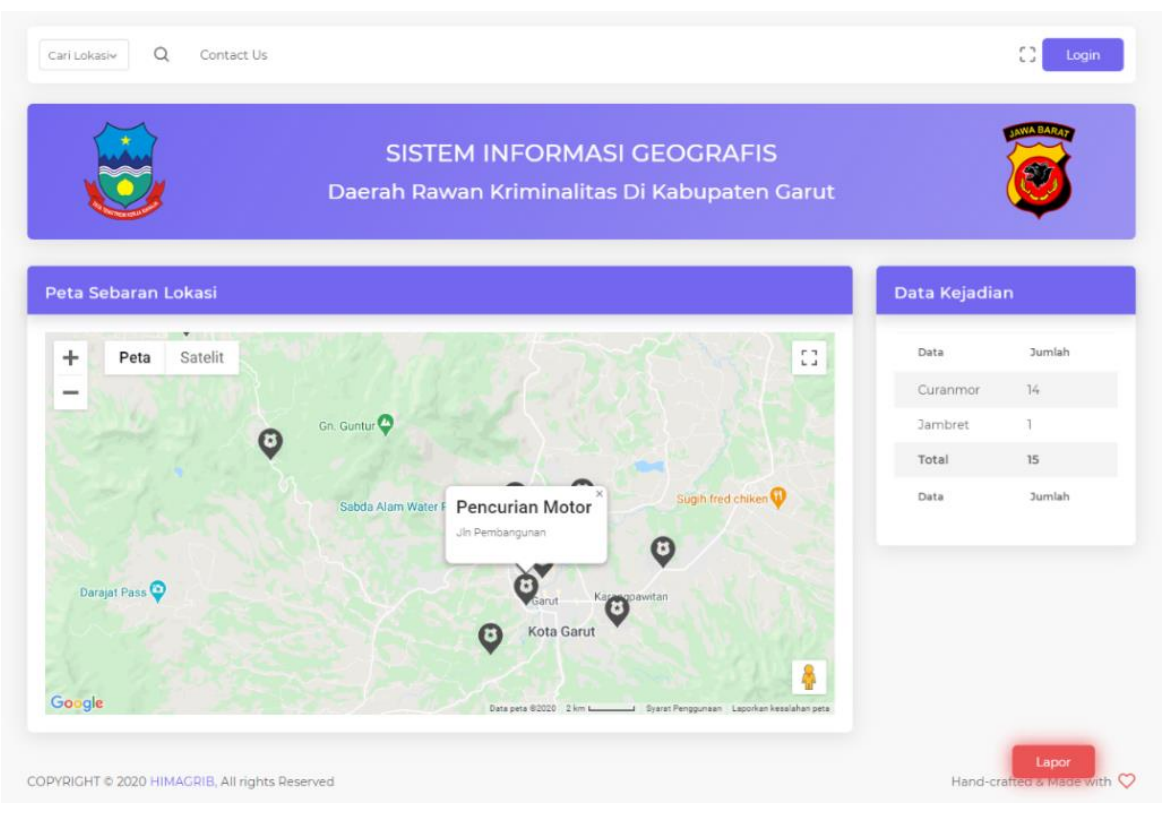

Gambar 5: Halaman Umum

\section{F. Transition}

Pada tahapan ini merupakan tahap pengujian, metode ynag digunakan dalam pengujian adalah Black Box Testing [14] yang bertujuan untuk menguji fungsionalitas fitur maupun menu dengan maksud untuk mencari bug (error) [15] pada sistem yang sudah dibuat. Dibawah ini adalah hasil dari pengujian black box testing pada Sistem Infromasi Geografis Darah Rawan Kriminalitas di Kabupaten Garut yang disajikan dalam Tabel 2.

Tabel 2: Hasil Pengujian

\begin{tabular}{|c|c|c|c|c|}
\hline Aktivitas & Kelas Pengujian & Skenario Pengujian & $\begin{array}{c}\text { Hasil yang } \\
\text { diharapkan }\end{array}$ & Keterangan \\
\hline \multirow[t]{2}{*}{ Login } & $\begin{array}{l}\text { dilakukan pengujian } \\
\text { masuk ke sistem sesuai } \\
\text { dengan nama pengguna } \\
\text { dan kata sandi }\end{array}$ & $\begin{array}{l}\text { Memasukan nama } \\
\text { pengguna dan kata } \\
\text { sandi dengan benar }\end{array}$ & Login berhasil & Berhasil \\
\hline & $\begin{array}{l}\text { dilakukan pengujian } \\
\text { masuk ke sistem yang } \\
\text { tidak sesuai dengan nama } \\
\text { pengguna dan kata sandi }\end{array}$ & $\begin{array}{l}\text { Memasukan nama } \\
\text { pengguna dan kata } \\
\text { sandi tidak benar }\end{array}$ & Login gagal & Berhasil \\
\hline Logout & Melakukan logout & $\begin{array}{l}\text { Memilih keluar dari } \\
\text { system }\end{array}$ & Keluar dari system & Berhasil \\
\hline \multirow[t]{4}{*}{ Mengelola Kategori } & $\begin{array}{l}\text { Melakukan pengujian } \\
\text { pada menu kelola } \\
\text { kategori }\end{array}$ & $\begin{array}{l}\text { Memilih menu kelola } \\
\text { kategori }\end{array}$ & $\begin{array}{l}\text { Menampilkan halaman } \\
\text { kelola kategori }\end{array}$ & Berhasil \\
\hline & $\begin{array}{l}\text { Melakukan tambah } \\
\text { kategori }\end{array}$ & Tambah kategori & $\begin{array}{l}\text { Data kategori } \\
\text { bertambah }\end{array}$ & Berhasil \\
\hline & Melakukan edit kategori & Edit kategori & $\begin{array}{l}\text { Data kategori } \\
\text { terbaharui }\end{array}$ & Berhasil \\
\hline & $\begin{array}{l}\text { Melakukan hapus } \\
\text { kategori }\end{array}$ & Hapus kategori & Data kategori terhapus & Berhasil \\
\hline
\end{tabular}




\begin{tabular}{|c|c|c|c|c|}
\hline Aktivitas & Kelas Pengujian & Skenario Pengujian & $\begin{array}{l}\text { Hasil yang } \\
\text { diharapkan }\end{array}$ & Keterangan \\
\hline \multirow[t]{4}{*}{ Mengelola lokasi } & $\begin{array}{l}\text { Melakukan pengujian } \\
\text { pada menu kelola lokasi }\end{array}$ & $\begin{array}{l}\text { Memilih menu kelola } \\
\text { kategori }\end{array}$ & $\begin{array}{l}\text { Menampilkan halaman } \\
\text { kelola kategori }\end{array}$ & Berhasil \\
\hline & Melakukan tambah lokasi & tambah lokasi & Data lokasi bertambah & Berhasil \\
\hline & Melakukan edit lokasi & Edit lokasi & Data lokasi terbaharui & Berhasil \\
\hline & Melakukan hapus lokasi & Hapus lokasi & Data lokasi terhapus & Berhasil \\
\hline \multirow[t]{2}{*}{ Mengelola laporan } & $\begin{array}{l}\text { Melakukan pengujian } \\
\text { pada menu menu kelola } \\
\text { laporan }\end{array}$ & $\begin{array}{l}\text { Memilih menu kelola } \\
\text { laporan }\end{array}$ & $\begin{array}{l}\text { Menampilkan halaman } \\
\text { kelola lapoean }\end{array}$ & Berhasil \\
\hline & Melakukan hapus laporan & Hapus laporan & Laporan terhapus & Berhasil \\
\hline \multirow[t]{2}{*}{$\begin{array}{l}\text { Mengelola contact } \\
\text { user }\end{array}$} & $\begin{array}{l}\text { Melakukan pengujian } \\
\text { pada menu contact user }\end{array}$ & $\begin{array}{l}\text { Memilih menu contact } \\
\text { user }\end{array}$ & $\begin{array}{l}\text { Menampilkan halaman } \\
\text { contact user }\end{array}$ & Berhasil \\
\hline & $\begin{array}{l}\text { Melakukan hapus contact } \\
\text { user }\end{array}$ & Hapus contact user & $\begin{array}{l}\text { Data contact user } \\
\text { terhapus }\end{array}$ & Berhasil \\
\hline \multirow[t]{2}{*}{$\begin{array}{l}\text { Konfigurasi } \\
\text { aplikasi }\end{array}$} & $\begin{array}{l}\text { Melakukan pengujian } \\
\text { pada menu konfigurasi } \\
\text { aplikasi }\end{array}$ & $\begin{array}{l}\text { Memilih menu } \\
\text { konfigurasi aplikasi }\end{array}$ & $\begin{array}{l}\text { Menampilkan form } \\
\text { konfigurasi aplikasi }\end{array}$ & Berhasil \\
\hline & $\begin{array}{l}\text { Melakukan update } \\
\text { konfigurasi aplikasi }\end{array}$ & $\begin{array}{l}\text { Update konfigurasi } \\
\text { aplikasi }\end{array}$ & $\begin{array}{l}\text { Konfigurasi aplikasi } \\
\text { terbaharui }\end{array}$ & Berhasil \\
\hline Cari lokasi & $\begin{array}{l}\text { Melakukan pengujian } \\
\text { pada fitur cari }\end{array}$ & Cari lokasi & $\begin{array}{l}\text { Menampilkan hasil } \\
\text { pencarian }\end{array}$ & Berhasil \\
\hline \multirow[t]{3}{*}{ Contact us } & $\begin{array}{l}\text { Melakukan pengujian } \\
\text { pada firtur contact } u s\end{array}$ & Klik button contact us & $\begin{array}{l}\text { Menampilkan form } \\
\text { contact us }\end{array}$ & Berhasil \\
\hline & $\begin{array}{l}\text { Melakukan pengisian } \\
\text { form contact us }\end{array}$ & $\begin{array}{l}\text { Mnegisi form contact } \\
\text { us }\end{array}$ & Form lapor terisi & Berhasil \\
\hline & Mengirim contact us & Kirim contact us & $\begin{array}{l}\text { Data contact us } \\
\text { terkirim }\end{array}$ & Berhasil \\
\hline \multirow[t]{3}{*}{ Lapor } & $\begin{array}{l}\text { Melakukan pengujian } \\
\text { pada fitur lapor }\end{array}$ & Klik button lapor & $\begin{array}{l}\text { Menampilkan from } \\
\text { lapor }\end{array}$ & Berhasil \\
\hline & $\begin{array}{l}\text { Melakukan pengisian } \\
\text { form lapor }\end{array}$ & Mengisi form lapor & Form lapor terisi & Berhasil \\
\hline & Mengirim lapor & Kirim lapor & Data lapor terkirim & Berhasil \\
\hline
\end{tabular}

Bersumber dari hasil black-box testing pada Tabel 2, sistem yang sudah dibangun tersebut tidak terdapat kesalahan secara fungsionalitas sistem sehingga dapat diimplementasikan dan digunakan dengan baik.

\section{G. Pembahasan Hasil}

Setelah dilakukan penelitian dengan output berupa sistem informasi geografis kawasan rawan kriminal, dimana sistem tersebut mampu menghimpun data kriminalitas sesuai dengan titik lokasi perkara untuk masyarakat, serta masyarakat dapat mengetahui titik mana saja yang sering terjadi kriminalitas berdasarkan banyaknya titik kejadian perkara pada sistem informasi geografis. Dari penelitian yang telah dilakukan, penelitian ini memberikan kontribusi kepada pengetahuan berupa diterapkannya sistem informasi geografis di lingkungan kepolisian sebagai media penyebaran informasi titik kriminalitas dan memberikan saluran bagi masyarakat untuk melakukan pelaporan secara online tetang kritik, saran ataupun pengaduan lainnya. 


\section{KESIMPULAN}

Berdasarkan dari tujuan dalam penelitian ini, penggunaan metodologi RUP pada pembangunan sistem yang menyajikan data kriminalitas dapat di implementasikan dengan baik, sistem tersebut juga dapat memberikan informasi kepada masyarakat mengenai titik lokasi kejadian kriminalitas sehingga masyarakat bisa lebih meningkatkan kewaspadaannya untuk mengurasi tingkat kriminalitas.

\section{DAFTAR PUSTAKA}

[1] L. Fitriani and T. Faturochman, "Rancang Bangun Sistem Informasi Geografis Pariwisata Dan Industri Berbasis Web," J. Algoritm., 2019.

[2] R. Setiawan, D. Kurniadi, and H. Bunyamin, "Perancangan Sistem Pengelolaan Penanggulangan Bencana Alam Garut Berbasis Sistem Informasi Geografis," J. Algoritm.

[3] Andrianto and M. Jazman, "Sistem Informasi Geografis Pemetaan Titik Lokasi Daerah Rawan Kriminalitas Kota Solok (Studi Kasus: Polres Solok Kota)," Semin. Nas. Teknol. Inf. Komun. dan Ind., 2018.

[4] S. Rahayu, "Perancangan Sistem Informasi Geografis Pemetaan Sebaran Alumni," J. Algoritm., vol. 15, no. 2, pp. 113-119, 2019, doi: 10.33364/algoritma/v.15-2.113.

[5] E. Wildayanti, D. Tresnawati, and R. Setiawan, "Rancang Bangun Profil Wisata Dengan Sistem Informasi Geografis Perum Perhutani Kesatuan Pemangku Hutan Garut," J. Algoritm., 2015.

[6] S. Bagian, J. Kejahatan, and K. B. Android, "Kriminalitas Pada Ditreskrimum Polda."

[7] R. Setiawan and L. H. Agustin, "Pengembangan Aplikasi Controlling Tugas Akhir Berbasis Web Sisi Koordinator, Dan Pemangku Keputusan," J. Algoritm., 2016.

[8] M. Shalahuddin and A. S. Rosa, "Rekayasa perangkat lunak terstruktur dan berorientasi objek," Bandung Inform., 2013.

[9] B. Nugroho, "PHP dan MySQL dengan editor Dreamweaver MX," Yogyakarta Andi, 2004.

[10] Y. Yudhanto and H. A. Prasetyo, Mudah menguasai framework laravel. Elex Media Komputindo, 2019.

[11] A. M. Rudianto, Pemrograman Web Dinamis menggunakan PHP dan Mysql. Yogyakarta: C.V ANDI OFFSET, 2011.

[12] A. Husein, Proyek Membangun Responsive Web Desain dengan Bootstrap 3 dan 4. Yogyakarta: CV.Lokomedia, 2015.

[13] A. Maulana and S. Rahayu, "Rancang Bangun Aplikasi Panduan Cara Membuat Identitas Diri Untuk Penyandang Autis," J. Algoritm., vol. 17, no. 1, pp. 1-7, 2020.

[14] M. S. Mustaqbal, R. F. Firdaus, and H. Rahmadi, "Pengujian Aplikasi Menggunakan Black Box Testing Boundary Value Analysis (Studi Kasus : Aplikasi Prediksi Kelulusan SNMPTN),” 2015.

[15] V. Febrian, M. R. Ramadhan, M. Faisal, and A. Saifudin, "Pengujian pada Aplikasi Penggajian Pegawai dengan menggunakan Metode Blackbox," J. Inform. Univ. Pamulang, vol. 5, no. 1, pp. 61-66, 2020. 